\title{
A GENERAL METHOD FOR ACYLATION OF 1,3-DIALKYL-SUBSTITUTED BARBITURIC AND 2-THIOBARBITURIC ACIDS
}

\author{
Lucjan Strekowski. " Mohamed A. Ismail ${ }^{\text {st }}$ and Hanati H. Zoorob"* \\ $\$$ Department of Chemistry, Georgia State University, Atlanta. Gcorgia 30303. USA \\ ${ }^{\ddagger}$ Chemistry Department. Faculty of Science. Al-Mansoura University, Egypt
}

\begin{abstract}
A sodium derivative of 1,3-dimethylbarbituric acid or 1,3-diethyl-2-thiobarbituric acid undergoes an efficient acylation reaction at the position 5 by treatment with an acyl chloride in the presence of pyridine.
\end{abstract}

There is a continuing interest in development of new methodologies for the introduction of a substituent at the position 5 of barbituric acids, which is due to the wide spectrum of biological activity of the 5-functionalized derivatives (1-3). Surprisingly, however, only a few reports have described acylation of 1,3-dimethylbarbituric acid (1). Benzoylation can be accomplished by treatment of 1 with benzoyl chloride in the presence of triethylamine and zinc cyanide (3) or by the reaction of a sodium derivative of 1 with benzoyl chloride (4). Compound 1 can also be acetylated by treatment with a large excess of acetic anhydride (5), but similar preparations of higher alkanoyl derivatives have not been reported. As a part of this work we have found that a prolonged heating of (i) 1 with an alkanoyl chloride in the presence of triethylamine or (ii) a sodium salt of 1 with the alkanoyl chloride in various solvents produced only traces of the desired 5-alkanoyl derivative of 1 . In many cases the starting material 1 has been isolated in high yield from the crude mixtures.

We found, however, that efficient acylation of 1 is achieved by the reaction of its sodium derivative 3 with an alkanoyl chloride in the presence of pyridine. This is illustrated in Scheme by the preparation of 5 ( $\omega$-chloroalkanoyl)-substituted 1,3-dimethylbarbituric acids 8 and 9 from 1 and the respective $\omega$ chloroalkanoyl chlorides 4 and 5. 1,3-Diethyl-2-thiobarbituric acid (2) is also efficiently acylated by this method, as shown by the synthesis of compounds 10-12. Obviously, pyridine undergoes a reaction with acid chloride to generate an intermediate product, such as 7 , that is more reactive than the starting acid chloride.

In a typical run, a solution of 1 or $2(10 \mathrm{mmol})$ in THF $(10 \mathrm{~mL})$ was added to a suspension of $\mathrm{NaH}$ $(0.3 \mathrm{~g}, 95 \%, 12 \mathrm{mmol})$ in THF $(50 \mathrm{~mL})$, and the mixture was heated under reflux and a nitrogen atmosphere for $2.5 \mathrm{~h}$. After cooling the resultant solution of 3 was treated with an acid chloride (15 mmol) and then pyridine $(1 \mathrm{~mL})$, and the mixture was stirred at $40{ }^{\circ} \mathrm{C}$ until a GC analysis showed the absence of 1 or $2(24-36 \mathrm{~h})$. Concentration on a rotary evaporator was followed by treatment of the residue with water ( 5 $\mathrm{mL})$ and then extraction of the mixture with chloroform $(3 \times 20 \mathrm{~mL})$. Drying of the extract $\left(\mathrm{MgSO}_{4}\right)$ and concentration was followed by crystallization of the residue from an appropriate solvent (6). 


\section{Scheme}

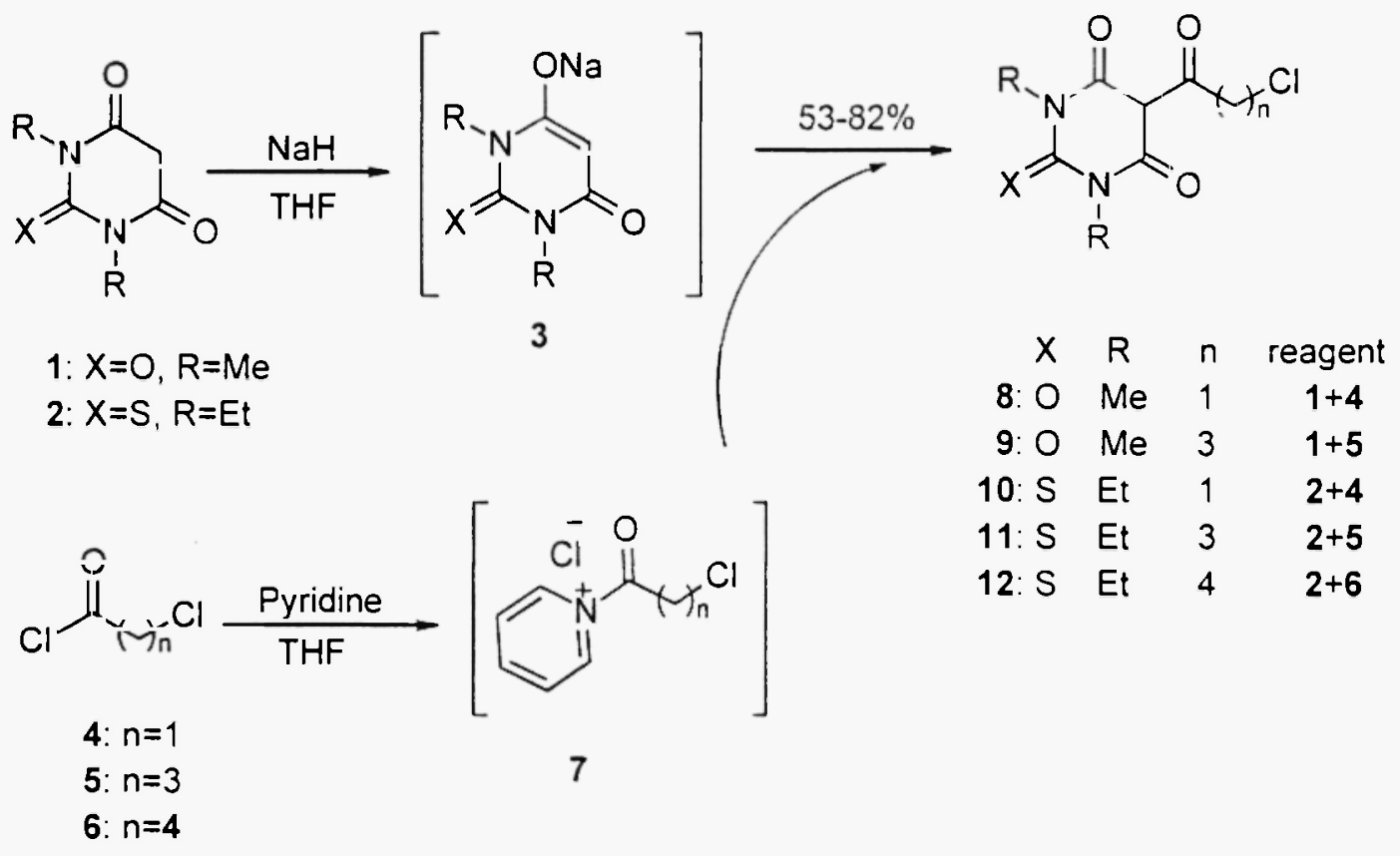

\section{Acknowledgment}

This work was supported in part by the Educational Aid Program at DuPont Co. Mr. Ismail is a CHANNEL student from Al-Mansoura University.

\section{References and Notes}

(1) H.H. Zoorob, M. Abou-Elzahab, M. Abdel-Mogib, M.A. Ismail and M. Abdel-Hamid, Arzneim. Forsch./Drug Res. 47 (II), 958 (1997); and references cited therein

(2) H.H. Zoorob, M. Abou-Elzahab, M. Abdel-Mogib and M.A. Ismail, Tetrahedron 52, 10147 (1996); and references cited therein

(3) D.L. Lee and C.G. Carter (Stauffer Chemical Co.), U.S. Patent 4, 797, 147 (Jan.10, 1989)

(4) D.V. Tinh and W. Stadlbouer, J. Heterocycl. Chem. 33, 1025 (1996)

(5) P. Wolfgang and S. Karl-Heinz, Ann. 612, 158 (1957)

(6) All compounds gave satisfactory elemental analyses and the given structures are fully consistent with ${ }^{1} \mathrm{H}$ and ${ }^{13} \mathrm{C}$ NMR data. Compound, yield, mp: 8, 82\%, 101-102 ${ }^{\circ} \mathrm{C}$ (from EtOH); 9, 67\%, 56-57 ${ }^{\circ} \mathrm{C}$ (from ether/hexanes); 10, 65\%, 91-92 ${ }^{\circ} \mathrm{C}$ (from ether/hexanes); $11,57 \%, 48-49{ }^{\circ} \mathrm{C}$ (from ether/hexanes); $12,53 \%, 50-51{ }^{10} \mathrm{C}$ (from ether/pentanes)

\section{Received on November 11, 1998}

